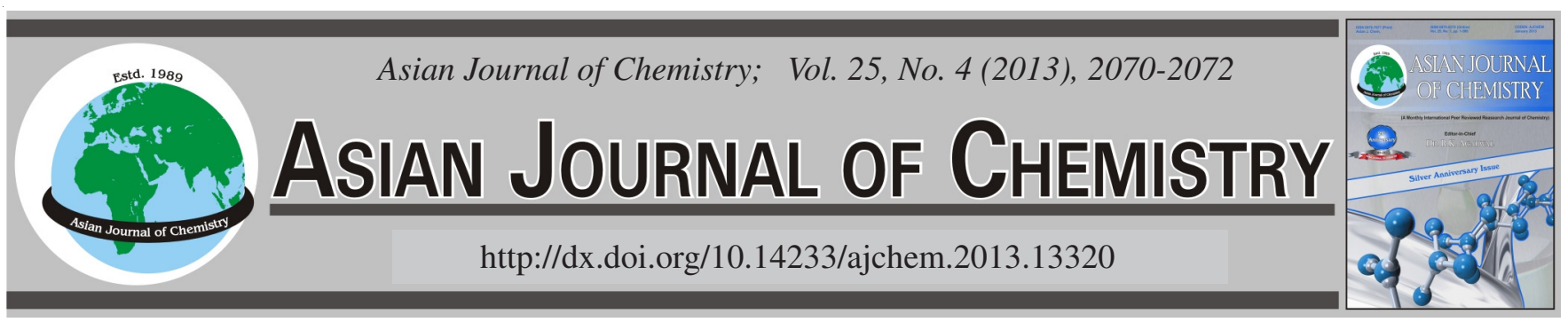

\title{
Novel Synthesis and Characterization of Some Pyrimidine \\ Derivatives of Oxadiazoles, Triazole and 1,3,4-Thiadiazoles
}

\author{
B. Andrews* ${ }^{*}$ and Mansur Ahmed
}

Department of Chemistry, Islamiah College, Vaniyambadi-635 751, India

*Corresponding author: E-mail: bandrews2006@yahoo.com

\begin{abstract}
In the present investigation, synthetic methods of 4-aryl-6-methyl-2-oxo-1,2,3,4-tetrahydro pyrimidine-(5)-1,3,4-thiadiazole-2-amine (3) and 4-aryl-6-methyl-2-oxo-1,2,3,4-tetrahydro pyrimidine-(5)-1,3,4-oxadiazole-2-amine (3a) and 4-aryl-6-methyl-2-oxo-1,2,3,4-tetrahydro pyrimidine-(5)-1,3,4-triazole-2-thiol derivative (3b) are described. Compound $\mathbf{1}$ is converted to carbothiamide $\mathbf{2}$ by the reaction with ethyl ester followed by thiosemicarbazide. Compound $\mathbf{2}$ acts as key intermediate for all series of the final compounds. In one pathway, $\mathbf{2}$ is converted to corresponding thiadiazole 3 by treatment with conc. $\mathrm{H}_{2} \mathrm{SO}_{4}$ and $\mathrm{NH}_{3}$ and compound 3a by treatment with $\mathrm{I}_{2}$ followed by $\mathrm{KI}$ and $\mathrm{NaOH}$ and compound $\mathbf{3 b}$ by treatment with $10 \%$ of $\mathrm{NaOH}$ to furnish the final compound. Structural elucidation is accomplished by IR, ${ }^{1} \mathrm{H}$ NMR and mass spectral data of the synthesized compounds.
\end{abstract}

Key Words: Pyrimidine, Thiadiazole, Oxadiazole, Triazole, Carbothiamide, Thiosemicarbazide.

ᄂ - - - - - - - - - - - - - - - - - - - - - - - - - - - -

\section{INTRODUCTION}

Literature survey revealed the importance of pyrimidine derivatives and antimicrobial agent ${ }^{1}$, which are found to be associated with variety of biological activities such as insecticidal, antimicrobial, antiviral etc., pyrimidine derivatives ${ }^{2-5}$ are also known to possess antiinflammatory activity. Moreover incorporation of pyrimidine ester $^{6-8}$ with thiosemicarbazide compound has produced new organic compound ${ }^{9,10}$ motivated by the above mentioned facts herein is reported. The synthesis of new compound and their characterization of new pyrimidine series conjugated with 1,3,4-thiadiazole ${ }^{11}, 1,3,4$-oxadiazole ${ }^{12}$ and 1,3,4-triazole ${ }^{13,14}$ rings, respectively.

\section{EXPERIMENTAL}

Melting points of all the synthesized compounds were taken in open capillaries and are uncorrected. IR spectra $(\mathrm{KBr})$ were recorded on a Perkin-Elmer 1300 FT IR spectrometer and ${ }^{1} \mathrm{H}$ NMR were determined on a Bruker WM-500 $(500 \mathrm{MHz}$ FT NMR) spectrometer using TMS as internal standard, mass spectra were recorded on GCMS spectrometer-Jeol GC mate spectrometer. All compounds gave satisfactory micro analytical results.

Purity of the synthesized compound was checked by TLC using Silica gel-G Plates using water-benzene as a solvent. Pyrimidine 1 were prepared by reported methods.

4-Aryl-6-methyl-2 oxo-1,2,3,4-tetrahydro pyrimidine(5)-carbothioamide 2: An equimolar mixture of compound
$1(0.01 \mathrm{~mol})$ and thiosemicarbazide $(0.01 \mathrm{~mol})$ in acetone was refluxed for 8-10 h and allow to cool and yellow solid was recrystallized was carried out from alcohol (Scheme-I). m.p. of the compound is $146^{\circ} \mathrm{C}$ yield $75 \%$. IR $\left(\mathrm{KBr}, v_{\max }, \mathrm{cm}^{-1}\right)$ : 3242, 3115 (N-H str.), 2978 (C-H str, Ar-H), 1724 (C=O Str, CONH), 1647 (C=N str.), 1313 (C-N str.), 1090 (C=S str.). ${ }^{1} \mathrm{H}$ NMR (acetone, $\delta): 8.34(1 \mathrm{H}, \mathrm{br}, \mathrm{s}), 7.82-7.80(1 \mathrm{H}, \mathrm{m}), 6.92(1 \mathrm{H}$, br, s), 5.38 (5H, d), 2.10-1.99 (3H, m), 1.17-1.15 (3H, s). Mass spectra: $\mathrm{m} / \mathrm{z}=305 \mathrm{M}^{+}$(base peak).

4-Aryl-6-methyl-2-oxo-1,2,3,4-tetrahydro pyrimidine(5)-1,3,4-thiadiazole-2-amine 3: Carbothioamide 2. (0.01 mol) was dissolved in $5 \mathrm{~mL}$ conc. $\mathrm{H}_{2} \mathrm{SO}_{4}$. This solution was stirred at room temperature for a few minutes and left overnight. It was then poured on crushed ice. The resulting suspension was kept in ammonical water for $2 \mathrm{~h}$ filtered and recrystallized from alcohol as white crystals (Scheme-II). m.p. $120^{\circ} \mathrm{C}$, yield $82 \%$. IR (KBr, $\left.v_{\max }, \mathrm{cm}^{-1}\right): 3328,3173$ (N-H str.), 3105 (C-H str. Ar-H), 2979 (C-H str. $\left.\mathrm{CH}_{2}\right), 1669$ (C=O str. CONH), 1574 (C=N str.), 1118 (C-S str.). ${ }^{1} \mathrm{H}$ NMR (acetone, $\left.\delta\right): 9.24(1 \mathrm{H}$, s), $8.69(1 \mathrm{H}, \mathrm{s}), 7.30-7.27(1 \mathrm{H}, \mathrm{m}), 5.43(1 \mathrm{H}, \mathrm{d}, J=3.0 \mathrm{~Hz})$, 4.11-4.01 (2H, m), $2.45(3 \mathrm{H}, \mathrm{s})$. Mass spectra: $\mathrm{m} / \mathrm{z}=287 \mathrm{M}^{+}$ (base peak).

4-Aryl-6-methyl-2-oxo-1,2,3,4-tetrahydro pyrimidine(5)-1,3,4-oxadiazole-2-amine 3a: Compound 2. (0.01 mol) was added into $10 \mathrm{~mL}$ of $10 \% \mathrm{NaOH}$ with cooling and shaking iodine solution in KI (10\%) was added gradually and shaking until the iodine colour persisted. Heating was continued for 
<smiles>[X]C1=NC(C)=C(C(=O)OCC)C(c2ccccc2)N1</smiles>

compound-1<smiles>NNC(N)=S</smiles><smiles>[X]C1NC(C)=C(C(=O)NNC(N)=S)C(c2ccccc2)N1</smiles>

Scheme-I: Synthesis and reaction of 4-aryl-6-methyl pyrimidine derivatives

5-6 $\mathrm{h}$ and cooled and poured onto ice-cold water. The solution was filtered washed with cold water and little amount of carbon disulphide was added. The product was recrysta-llized from alcohol (Scheme-II). m.p. $160{ }^{\circ} \mathrm{C}$, yield $85 \%$. IR (KBr, $v_{\max }$, $\mathrm{cm}^{-1}$ ): 3245, 3117 (N-H str.), 3060 (C-H str. Ar-H), 2979 (C-H Str, $\mathrm{CH}_{2}$ ), 1649 (C=N str.), 1420 (C-O-C str.), 1699 (C=O str.).
${ }^{1} \mathrm{H}$ NMR (acetone, $\left.\delta\right): 8.40$ (1H, br), 7.42-7.3 (5H, m), 7.327.40 (1H, m), 6.95 (1H, br), 5.39 (1H, d, $J=3.5 \mathrm{~Hz}), 2.40$ (3H, s). Mass spectra: $\mathrm{m} / \mathrm{z}=271 \mathrm{M}^{+}$(base peak).

4-Aryl-6-methyl-2-oxo-1,2,3,4-tetrahydro pyrimidine(5)-1,3,4-triazole-2-thiol (3b): To the aqueous solution of sodium hydroxide $(10 \%, 40 \mathrm{~mL})$ was added in carbothioamide 2. $(0.01 \mathrm{~mol})$ and the reaction mixture refluxed gently for $2 \mathrm{~h}$. The resulting solution was treated with charcoal, cooled and filtered. The filtrate was acidified with $10 \% \mathrm{HCl}$ and adjusted pH 5-6. The solid mass was precipitated, filtered, washed with ice-cold water and re-crystallized from alcohol as white crystals (Scheme-II). m.p. $205^{\circ} \mathrm{C}$, yield $80 \%$. IR $\left(\mathrm{KBr}, \mathrm{v}_{\max }, \mathrm{cm}^{-1}\right)$ : 3328, 3173 (N-H str.), 3105 (C-H str. Ar-H), 2979 (C-H str. $\mathrm{CH}_{2}$ ), 1669 (C=O str. CONH), 1574 (C=N str.), 1118 (C-S str.). ${ }^{1} \mathrm{H}$ NMR (acetone, $\left.\delta\right): 9.24(1 \mathrm{H}, \mathrm{s}), 8.69(1 \mathrm{H}, \mathrm{s}), 7.30-$ $7.27(1 \mathrm{H}, \mathrm{m}), 5.43(1 \mathrm{H}, \mathrm{d}, J=3.0 \mathrm{~Hz}), 4.11-4.01(2 \mathrm{H}, \mathrm{m})$, $2.45(3 \mathrm{H}, \mathrm{s})$. Mass spectra: $\mathrm{m} / \mathrm{z}=287 \mathrm{M}^{+}$(base peak).

\section{RESULTS AND DISCUSSION}

The key intermediate used for the synthesis of all series of the final compounds was 4-aryl-6-methyl-2-oxo-1,2,3,4 tetrahydro pyrimidine-(5)-3-carbothioamide 2 , which in turn was prepared by the reaction of 4-aryl-6-methyl-2-oxo-1,2,3,4tetrahydro pyrimidine-(5)-carboxylic acid ethyl ester-1 with thiosemicarbazide in presences of acetone. Formation of $\mathbf{2}$ was confirmed by the presence of N-H stretching peaks at 3328 and $3173 \mathrm{~cm}^{-1}$ and $\mathrm{C}=\mathrm{O}$ stretching peaks at $1669 \mathrm{~cm}^{-1}$ in IR and multiplet at $8.34 \mathrm{~cm}^{-1}$ for NH.NH.C $=\mathrm{S} . \mathrm{NH}_{2}$ group in ${ }^{1} \mathrm{H}$<smiles>[X]C1=NC(c2ccccc2)C(c2nnc(N)s2)=C(C)NC([R])C1(CO)C(=O)O</smiles>

Scheme-II: Synthesis and reaction of 4-aryl-6-methyl pyrimidine derivatives 
TABLE-1

PHYSICAL AND ANALYTICAL DATA OF COMPOUNDS 2, 3, 3A AND 3B

\begin{tabular}{|c|c|c|c|c|c|c|c|}
\hline \multirow{2}{*}{ Compounds } & \multirow{2}{*}{ m.f. } & \multirow{2}{*}{ m.w. } & \multirow{2}{*}{ Yield (\%) } & \multirow{2}{*}{ m.p. $\left({ }^{\circ} \mathrm{C}\right)$} & \multirow{2}{*}{ Time (h) } & \multicolumn{2}{|c|}{ Calcd. (\%) } \\
\hline & & & & & & $\mathrm{C}$ & $\mathrm{N}$ \\
\hline 2 & $\mathrm{C}_{13} \mathrm{H}_{15} \mathrm{~N}_{5} \mathrm{O}_{2} \mathrm{~S}_{1}$ & 305 & 75 & 146 & $8-10$ & $(51.35)$ & (23.03) \\
\hline 3 & $\mathrm{C}_{13} \mathrm{H}_{13} \mathrm{~N}_{5} \mathrm{O}_{1} \mathrm{~S}_{1}$ & 287 & 82 & 120 & - & (54.59) & (24.48) \\
\hline $3 \mathbf{a}$ & $\mathrm{C}_{13} \mathrm{H}_{13} \mathrm{~N}_{5} \mathrm{O}_{2}$ & 271 & 85 & 160 & $5-6$ & (57.82) & (25.93) \\
\hline $3 \mathbf{b}$ & $\mathrm{C}_{13} \mathrm{H}_{13} \mathrm{~N}_{5} \mathrm{O}_{1} \mathrm{~S}_{1}$ & 287 & 80 & 205 & $2-2.5$ & (54.59) & (24.48) \\
\hline
\end{tabular}

NMR spectra. Treatment of compound 2 with conc. $\mathrm{H}_{2} \mathrm{SO}_{4}$ and $\mathrm{NH}_{3}$, furnished 4-aryl-6-methyl-2-oxo-1,2,3,4-tetrahydro pyrimidine-(5)-1,3,4-thiadiazole-2-amine (3). The structure of 3 was elucidated on the basis of C-S-C linkage in the thiadiazol ring, which caused a sharp absorption band at $1102 \mathrm{~cm}^{-1}$ in its IR spectrum.

${ }^{1} \mathrm{H}$ NMR spectrum showed a fine singlet at $\delta 4.11$ due to $\mathrm{NH}_{2}$ functionality confirmations of their structure were obtained through spectral and analytical data (physical and analytical data are given in Table-1). IR and ${ }^{1} \mathrm{H}$ NMR spectral data revealed carbonyl absorption band at $1725 \mathrm{~cm}^{-1}$ of $\mathrm{NH}-\mathrm{CO}-\mathrm{NH}$ group, N-O stretching band at $1355 \mathrm{~cm}^{-1}$ aliphatic $\mathrm{C}-\mathrm{H}$ and aromatic C-H stretching at 2979 and $3105 \mathrm{~cm}^{-1}$ group of pyrimidine moiety 3. Mass spectrum also supported the proposed structure by viewing molecular ion peak at $\mathrm{m} / \mathrm{z}=$ $287 \mathrm{M}^{+}$.

In another pathway, 2 underwent ready heterocyclization upon its reaction with $\mathrm{I}_{2}$ followed by $\mathrm{KI}$ and added $10 \% \mathrm{NaOH}$ with cooling and shaking to afford 4-aryl-6-methyl-2-oxo1,2,3,4-tetrahydro pyrimidine-(5)-1,3,4-oxadiazole-2-amine 3a. In IR spectrum, bands in the range of 1735 and $1699 \mathrm{~cm}^{-1}$ were obtained due to carbonyl stretching and C-O-C stretching range from 1420 and $1465 \mathrm{~cm}^{-1}$. In the ${ }^{1} \mathrm{H}$ NMR spectrum, signal were found at $\delta 5.39$ which showed the presence of oxo-diazol and $\mathrm{NH}_{2}$ group in ring.

The assigned structure of $\mathbf{3 a}$ was based on the obtained analytical and spectral data. The mass spectrum also supported the proposed structure by viewing molecular ion peak at $\mathrm{m} / \mathrm{z}$ $=271 \mathrm{M}^{+}$.

In another path way treatment of compound 2 with $\mathrm{NaOH}$ furnished 4-aryl-6-methyl-2-oxo-1,2,3,4-tetrahydro pyrimidine(5)-1,3,4-triazole-2-thiol (3b). The structure of $\mathbf{3 b}$ was elucidated on the basis of C-N-C linkage in the triazole ring, which caused a sharp absorption band at $1102 \mathrm{~cm}^{-1}$ in its IR spectrum.

${ }^{1} \mathrm{H}$ NMR spectrum showed a fine singlet at $\delta 4.11$ due to SH functionality confirmations of their structure were obtained through spectral and analytical data. (Physical and analytical data are given in Table-1) IR and ${ }^{1} \mathrm{H}$ NMR spectral data revealed carbonyl absorption band at $1725 \mathrm{~cm}^{-1}$ of $\mathrm{NH}-\mathrm{CO}-\mathrm{NH}$ group, $\mathrm{N}-\mathrm{O}$ stretching band at $1355 \mathrm{~cm}^{-1}$ aliphatic $\mathrm{C}-\mathrm{H}$ and aromatic
C-H stretching at 2979 and $3105 \mathrm{~cm}^{-1}$ group of pyrimidine moiety $\mathbf{3 b}$. Mass spectrum also supported the proposed structure by viewing molecular ion peak at $\mathrm{m} / \mathrm{z}=287 \mathrm{M}^{+}$.

\section{Conclusion}

A novel method for the synthesis of 1,3,4-oxadiazole, 1,3,4-triazole and 1,3,4-thiadiazole tetrahydro pyrimidine derivatives by modified compound 2 using conc. $\mathrm{H}_{2} \mathrm{SO}_{4}$ and $\mathrm{NH}_{3}$ for compound 3 and $\mathrm{I}_{2}$ followed by $\mathrm{KI}$ and $\mathrm{NaOH}$ for compound $\mathbf{3 a}$ and $\mathrm{NaOH}$ for compound $\mathbf{3 b}$ was developed for the first time and the yields are excellent. The mildness of the method together with ease of operation should largely extend the scope of this as an alternate substituted compound systems. These condition will tolerate the presence of different constituents on aromatic ring.

\section{ACKNOWLEDGEMENTS}

The authors are thankful to Principal and HOD of Chemistry, Islamiah College, Vaniyambadi, India for constant encouragement and providing necessary research facilities.

\section{REFERENCES}

1. C.O. Kape, Tetrahedron, 49, 6937 (1993).

2. C.O. Kape, Eur. J. Med. Chem., 35, 1043 (2000).

3. A. Manjula, B.V. Rao and P. Neelakantam, Synth. Commun., 34, 2665 (2004).

4. A.J. Zych, H.-J. Wang and S.A. Sakwa, Tetrahedron Lett., 51, 5103 (2010).

5. Garima, V.P. Srivastava and L.D.S. Yadav, Tetrahedron Lett., 51, 6436 (2010).

6. M.B. Moore and R.T. Rapela, J. Am. Chem. Soc., 68, 1657 (1946)

7. R.O. Atkinson, J. Chem. Soc., 1329 (1954).

8. R.S. Varma, J. Indian Chem. Soc., 81, 627 (2004).

9. M. Kidwai, R. Venkataramanan and B. Dave, J. Heterocycl. Chem., 39, 1045 (2002).

10. N.A. Ross and R.A. Burtsch, J. Heterocycl. Chem., 38, 1255 (2001).

11. V. Singh, V. Sapehiyia and G.L. Kad, Synthesis, 198 (2003).

12. X. Zou and G. Jin, J. Heterocycl. Chem., 38, 993 (2001).

13. N.A. Ross and R.A. Burtsch, J. Heterocycl. Chem., 38, 1255 (2001).

14. S.G. Jagadhani, S.B. Kale, N.R. Dalvi, M.S. More and B.K. Karale, Indian J. Heterocycl. Chem., 15, 335 (2006). 